\title{
Prevalence of Overweight and Obesity among Workers of a Hospital Unit
}

\author{
Paulo Henrique Panelli Ferreira, Carlos Antônio de Souza Teles Santos, Erenilde Marques de \\ Cerqueira, Michelle Teixeira Oliveira
}

\begin{abstract}
Objective:To evaluate the association between work activities, sociodemographic characteristics, life habits and health history with the profile of overweight and obesity of the health professionals of a hospital unit. Materials and Methods: A cross-sectional study, performed in a general hospital, in the closed (intensive care, emergency, surgical center) and open (other sectors) sectors, with 308 workers with different functions. A questionnaire addressing sociodemographic and labor characteristics was applied as well as anthropometric measurements were verified. Bivariate and descriptive analyzes were performed applying the chi-square test.Results:Waist circumference was inadequate in $32.5 \%$ of the workers. Regarding body mass index, $57.4 \%$ of the workers had inadequate classification, $16.4 \%$ with obesity. There was a significant association between overweight and age, increased waist circumference (WC), male sex, low schooling, offspring, sedentary lifestyle, smoking history, use of antihypertensive drugs, work in open areas and a number of worked hours up to 40 per week. It was identified a significant association between obesity and age, increased WC, female, offspring, sedentary lifestyle, smoking history, use of antihypertensive drugs and hypercholesterolemia, family history of early coronary disease, administrative and nursing work, work in open sectors and a number of worked hours up to 40 per week.Conclusion: There was a high percentage of overweight in the hospital workers investigated. The advancement of obesity in our society requires efforts aimed at prevention and control of diseases related to overweight. The inclusion of healthy eating habits and the stimulation of physical exercise are interventions that can be implemented in the work environment; and may act as facilitators of overweight control in this population.
\end{abstract}

Index Terms - occupational health, health professionals, risk factors, overweight, obesity.

\section{INTRODUCTION}

Highlight The technological advance in the last centuries has resulted in a significant change in the morbidity and mortality profile of the population. ${ }^{(1)}$ As the economic indicators of the poorest sections of the population improve, obesity gains importance in face of malnutrition, both in frequency and severity. ${ }^{(2)}$

Paulo Henrique Panelli Ferreira, Master's degree in Collective Health/UEFS. Daytime doctor in the obstetric ICU of the State Children's Hospital.Specialist in Intensive Care, General Surgery and Social Medicine by MEC.

Carlos Antônio de Souza Teles Santos, Biostatistician. Master's degree and PhD by Federal University of Bahia (UFBA). Researcher at FIOCRUZ and UFBA.Teacher of UEFS.

Erenilde Marques de Cerqueira, Nurse. Master's degree in Collective Health/UEFS.PhD in Medicine and Health/UFBA.Teacher of UEFS.

Michelle Teixeira Oliveira, Nurse. Master's degree from the Institute of Health Sciences of UFBA.PhD student in Collective Health by UEFS.
The World Health Organization (WHO) attributes to obesity epidemic behavior, mainly in the West, defining its confrontation as one of the great challenges of public health in the 21 st century. ${ }^{(3)}$ The multifactorial etiology of obesity and related diseases includes habits of life, which are implicated in both genesis and worsening of the prognosis, among which smoking is more highlighted, due to its impact on the populations of poor and developing countries. ${ }^{(4)}$ After other attempts, the WHO adopted body mass index (BMI) as an indicator of nutritional status. ${ }^{(5)}$ Waist circumference (WC) is cited as the best indicator of cardiovascular disease risk in epidemiological studies. ${ }^{(6,7)}$ Abdominal obesity, even in the absence of generalized obesity, adds coronary risk to this population. ${ }^{(8)}$

The American Heart Association classified obesity as the major modifiable risk factor for CVD and Metabolic Syndrome (MS). Studies relate sedentary lifestyle, obesity and low schooling to increased risk for MS. ${ }^{(10,11,12)}$

In Brazil, according to data provided by the 2002/2003 Family Budget Survey, it was observed that overweight affected about $40 \%$ of the adult population. In this subpopulation, $8.9 \%$ of adult men and $13.1 \%$ of adult women were obese, which ensured for obesity the title of risk factor most commonly found, in industrialized and developing countries. ${ }^{(13)}$

The issue of Brazilian worker health begins to strengthen, when researchers from the University of São Paulo (USP), in the 1970s, began to study the occupational health of hospital workers. ${ }^{(14)}$ With the advent of acquired immunodeficiency syndrome (AIDS) as an epidemic, health workers are now seen as a high-risk occupational category. ${ }^{(15)}$

The initiative to monitor risk factors in this population group is justified; therefore, their early identification may enable actions to promote health. The objective of this study was to evaluate the association between work activities, sociodemographic characteristics, life habits and health history with the profile of overweight and obesity of the employees of a hospital unit.

\section{MATERIALS AND METHODS}

It was a descriptive, exploratory, cross-sectional study. We used the quantitative approach to study servers working in a general hospital in the Northeast Region. Those employees aged over seventy years were excluded from the study, as were those with a period of service of less than one year and those on paid leave for health reasons, or as part of a career plan.

Statistical package STATA ${ }^{\circledR}$ was used to determine the 
minimum sample size, estimated at 308 employees. Workers with a BMI of less than or equal to $18.5 \mathrm{~kg} / \mathrm{m} 2$, considered to be underweight, were excluded. A total of 305 employees participated in the study, with several functions: nursing workers at the intermediate and higher levels, doctors, other professionals at the tertiary level (physiotherapists, social workers) and medium (nutrition), as well as support staff (maintenance, security, laundry) and administrative, performing its activities in the so-called closed units (surgical center, intensive care units and emergency) and also in other sectors of the hospital.

Data collection took place between February and April 2018, through the application of a collection instrument containing variables defined according to predictors of morbidity used in the V Brazilian Dyslipidemia and Atherosclerosis Guideline (obesity, hypertension, diabetes, sedentary lifestyle, smoking, abdominal waist, lifestyle), by a single researcher, also responsible for obtaining the anthropometric measures (weight, height, waist circumference).

The weight was measured using an analytical balance, mechanical type, TOLEDO brand, with a maximum capacity of $200 \mathrm{~kg}$, with the participant wearing light clothing and without footwear, with a fixed stadiometer coupled. The height was verified in orthostatic position, erect head, with upper limbs along the body, feet close and facing forward. To measure the abdominal circumference of the participants, a flexible measuring tape with a maximum length of two meters was used, from a manufacturer approved by the National Institute of Metrology (INMETRO), with a measurement of $0.1 \mathrm{~cm}$. The tape measure was placed at the level of the natural waist (narrower part of the abdomen, just below the last rib), without pressure.

The classification of abdominal fat accumulation, based on waist circumference (WC), used the cut-off points recommended by the WHO to predict the risk of metabolic complications, which establishes as an increased risk for men, WC values above $94 \mathrm{~cm}$. In females, it establishes as an increased risk of WC values above $80 \mathrm{~cm}$. Body mass index (BMI) was calculated by dividing the value of the weight in kilograms by the square of the height in meters. The value found was used to frame each participant in one of the following categories: underweight when the BMI was below $18.5 \mathrm{~kg} / \mathrm{m} 2$; when the BMI was between $18.6 \mathrm{~kg} / \mathrm{m} 2$ and $24.9 \mathrm{~kg} / \mathrm{m} 2$; overweight when the BMI was between $25.0 \mathrm{~kg}$ / $\mathrm{m} 2$ and $29.9 \mathrm{~kg} / \mathrm{m} 2$; obesity grade I when the BMI was between $30.0 \mathrm{~kg} / \mathrm{m} 2$ and $34.9 \mathrm{~kg} / \mathrm{m} 2$; grade II or severe obesity when the BMIwas between $35.0 \mathrm{~kg} / \mathrm{m} 2$ and $39.9 \mathrm{~kg} /$ $\mathrm{m} 2$; and, grade III or morbid obesity, when the BMI was above $40 \mathrm{~kg} / \mathrm{m} 2$.

The descriptive analysis applied absolute and percentage frequencies, presented in tables and graphs. Bivariate analyzes were performed using the chi-square test. The statistical treatment of the data was done using STATA ® software version 12 , adopting a significance level of $5 \%$.

The project was submitted for consideration and approval by the committee on research ethics (CRE) UEFS, CAAE: 74302617.3.0000.0053, in accordance with Resolution No. 466 of December 12, 2012, of the National Health Council, of the Ministry of Health, through the principles of autonomy, non-maleficence, beneficence, justice and equity; and confidentiality of information and anonymity were ensured. Participants received clarifications on the Free Informed Consent Term (FICT), prior to their signature by them.

\section{RESULTS}

Analyzing the group under a sociodemographic approach, a wide variation in age was identified, since a minimum of 19 years until the maximum of 69 years, with predominance of the range between 19 and 33 years $(26.6 \%)$, as well as female sex $(59.7 \%)$, with a significant association between age increase, with both obese and overweight. ( $p<0.0001)$ It was verified a significant association between males and overweight, with a prevalence of $64 \%(\mathrm{p}=0.047)$, as well as between female sex and obesity, with prevalence of $17.6 \%$. (p $=0.041)$ Most of the servers $(56.3 \%)$ claimed to hold a higher education diploma, an association between low schooling and overweight was found. ( $\mathrm{p}=0.033$ )Regarding race, blacks predominated $(80.8 \%)$, followed by a prevalence of $15.4 \%$ whites; and only $3.9 \%$ of workers who claimed to have another race. Regarding family aspects $(34.1 \%)$ did not have children, showing a significant association, both between overweight $(p=0.001)$ and obesity $(p=0.008)$ with having offspring. The percentage of those who lived in a stable union or were married was $52.6 \%$. Among the workers surveyed, $53.0 \%$ declared family income of up to five minimum wages. (Table 1)

TABLE 1 Distribution of workers according to selected characteristics and BMI $(n=305), 2018$

\begin{tabular}{|c|c|c|c|c|c|c|}
\hline \multirow[t]{2}{*}{$\begin{array}{l}\text { Sociodemographic } \\
\text { Characteristics }\end{array}$} & \multirow[b]{2}{*}{$\mathrm{N}$} & \multirow[b]{2}{*}{$\%$} & \multicolumn{2}{|l|}{ Obesity } & \multicolumn{2}{|c|}{ Overweight } \\
\hline & & & Prev \% & $p$-value & $\begin{array}{c}\text { Prev } \\
\%\end{array}$ & p-value \\
\hline Sex & & & & 0,041 & & 0,047 \\
\hline Female & 182 & 59.7 & 17.6 & & 52.7 & \\
\hline Male & 123 & 40.3 & 14.6 & & 64.2 & \\
\hline Age (years) & & & & $<0,0001$ & & $<0,0001$ \\
\hline $19-33$ & 81 & 26.6 & 9.88 & & 38.3 & \\
\hline $34-39$ & 75 & 24.6 & 16.00 & & 55.3 & \\
\hline $40-46$ & 76 & 24.9 & 19.74 & & 75.0 & \\
\hline$>=47$ & 73 & 25.9 & 20.55 & & 64.4 & \\
\hline Race / Skin color ${ }^{1}$ & & & & 0,667 & & 0,445 \\
\hline White & 47 & 15.3 & 14.9 & & 48.9 & \\
\hline Black & 249 & 80.8 & 17.1 & & 58.9 & \\
\hline Others & 12 & 3.9 & 8.3 & & 58.3 & \\
\hline Schooling & & & & 0,074 & & 0,033 \\
\hline Primary / medium & 131 & 43.7 & 16.79 & & 64.9 & \\
\hline Superior & 169 & 56.3 & 16.57 & & 52.7 & \\
\hline Marital Status & & & & 0,441 & & 0,208 \\
\hline Married / Stable union & 160 & 52.6 & 17.50 & & 60.6 & \\
\hline Single / widow & 144 & 47.4 & 14.58 & & 53.5 & \\
\hline Financial income & & & & 0,224 & & 0,371 \\
\hline 5 salaries or less & 161 & 53.0 & 19.88 & & 59.6 & \\
\hline More than 5 salaries & 143 & 47.0 & 12.59 & & 54.6 & \\
\hline Offspring & & & & 0,008 & & 0,001 \\
\hline None & 104 & 34.1 & 12.50 & & 46.2 & \\
\hline One & 92 & 30.2 & 18.48 & & 53.3 & \\
\hline Two & 72 & 23.6 & 18.06 & & 68.1 & \\
\hline More than two & 37 & 12.1 & 18.92 & & 78.4 & \\
\hline
\end{tabular}

It was observed a predominance of workers that exercised their activities in shifts $(66.9 \%)$, as did those working in up to 40 hours per week $(59.7 \%)$. We identified a significant association between obesity $(\mathrm{p}=0.016)$ and overweight $(\mathrm{p}=$ 0.013 ) with the number of working hours of up to 40 hours 
International Journal of New Technology and Research (IJNTR)

ISSN: 2454-4116, Volume-4, Issue-10, October 2018 Pages 74-78

per week. It was also found a predominance of workers who work in the so-called closed areas (surgical center, emergency and intensive care units) with $58.6 \%(\mathrm{n}=178)$. The exercise of the labor activity in the open sectors presented a significant association with overweight $(\mathrm{p}=0.026)$, as well as with obesity. ( $p=0.040)$ Among the total number of servers included in the study, $38.7 \%$ were doctors or nurses, $20 \%$ were nursing technicians, and the other functions accounted for $41.3 \%$ of the total. A statistically significant association of overweight and obesity was found with the exercise of administrative positions and with the category of nursing technicians. $(\mathrm{p}=0.052)$ (Table 2$)$

TABLE 2 Distribution of workers according to labor characteristics and BMI ( $\mathrm{n}=$ 305), 2018

\begin{tabular}{|c|c|c|c|c|c|c|}
\hline \multicolumn{3}{|c|}{ Characteristics } & \multicolumn{2}{|c|}{ Obesity } & \multicolumn{2}{|c|}{ Overweight } \\
\hline & $\mathrm{n}$ & $\%$ & $\begin{array}{c}\text { Prev } \\
\%\end{array}$ & $\mathrm{p}$-value & $\begin{array}{c}\text { Prev } \\
\%\end{array}$ & p-value \\
\hline Sector & & & & 0,040 & & 0,026 \\
\hline Opened & 126 & 41.4 & 21.4 & & 63.2 & \\
\hline Closed & 178 & 58.6 & 13.0 & & 52.3 & \\
\hline Worked hours & & & & 0,016 & & 0,013 \\
\hline Up to 40 hours & 182 & 59.7 & 20.3 & & 63.2 & \\
\hline More than 40 hours & 123 & 40,3 & 10.6 & & 48.8 & \\
\hline Work regime/shifts & & & & 0,274 & & 0,137 \\
\hline Yes & 204 & 66.9 & 14.7 & & 54.4 & \\
\hline No & 101 & 33.1 & 19.8 & & 63.4 & \\
\hline Function & & & & 0,052 & & 0,093 \\
\hline Doctors/Nurses & 118 & 38.7 & 9.3 & & 50.0 & \\
\hline Nursing technicians & 61 & 20.0 & 24.6 & & 65.6 & \\
\hline Administrative/others & 125 & 41.3 & 19.1 & & 60.3 & \\
\hline
\end{tabular}

1. Closed sector: workers fromemergeno, surgical center, intensive care units.

Regarding to previous family pathologies, the prevalence of overweight was similar in both groups, with or without a positive family history of premature coronary artery disease (CAD) (57.1\% and 58.3\%), and an association statistically significantwas observed between this and obesity. ( $\mathrm{p}=$ 0.032)When we began to observe the related sudden death's prevalence of infarction or stroke, there were very close rates of obesity in both groups, (16.3\% and 16.2\%), and no significant association was found in both cases with overweight and obesity.The same occurred when self-reported hypertension and elevated blood glucose were analyzed. When analyzing the profile of the workers who defined themselves as having hypercholesterolemia, a higher prevalence of overweight $(73.9 \%)$ was evidenced, showing a statistically significant association with overweight and obesity. ( $p=0.046$ ) The same occurred with the group of servants who called themselves antihypertensive users, who reached a prevalence of overweight of $74.3 \%(p=0.032)$, as described in table 3 .
TABLE 3 Distribution of workers according to pathological history and $\mathrm{BMI}(\mathrm{n}=$ 305), 2018.

\begin{tabular}{|c|c|c|c|c|c|c|}
\hline \multicolumn{2}{|c|}{$\begin{array}{l}\text { Previous family disease } \\
\text { history }\end{array}$} & \multicolumn{2}{|r|}{ Obesity } & \multicolumn{3}{|c|}{ Overweight } \\
\hline & $\mathrm{N}$ & $\%$ & Prev \% & $\begin{array}{c}\mathrm{p}- \\
\text { value }\end{array}$ & $\begin{array}{c}\text { Prev } \\
\%\end{array}$ & p-value \\
\hline Hypertension & & & & 0,075 & & 0,661 \\
\hline No & 207 & 67.8 & 16.9 & & 56.5 & \\
\hline Yes & 98 & 32.1 & 15.3 & & 59.2 & \\
\hline $\begin{array}{c}\text { Antihypertensive } \\
\text { users }\end{array}$ & & & & 0,071 & & 0,032 \\
\hline Yes & 35 & 11.5 & 25.7 & & 74.3 & \\
\hline No & 270 & 88.5 & 15.2 & & 55.2 & \\
\hline $\begin{array}{l}\text { Elevated blood } \\
\text { qlucose }\end{array}$ & & & & 0,791 & & 0,687 \\
\hline Yes & 30 & 9.9 & 13.3 & & 56.7 & \\
\hline No & 274 & 90.1 & 16.8 & & 57.3 & \\
\hline Hypercholesterolemia & & & & 0,046 & & 0,140 \\
\hline $\begin{array}{l}\text { Yes } \\
\text { No }\end{array}$ & $\begin{array}{c}46 \\
259\end{array}$ & $\begin{array}{l}15.1 \\
84.9\end{array}$ & $\begin{array}{l}19.6 \\
15.8\end{array}$ & & $\begin{array}{l}73.9 \\
54.4\end{array}$ & \\
\hline Sudden death history & & & & 0,507 & & 0,213 \\
\hline Yes & 49 & 16.1 & 16.3 & & 51.0 & \\
\hline No & 253 & 83.0 & 16.2 & & 58.1 & \\
\hline $\begin{array}{c}\text { Premature CAD } \\
\text { history }\end{array}$ & & & & 0,032 & & 0,973 \\
\hline Yes & 48 & 15.7 & 16.7 & & 58.3 & \\
\hline No & 247 & 80.9 & 15.4 & & 57.1 & \\
\hline
\end{tabular}

As for the anthropometric characteristics, waist circumference was inside of suitable parameters in $67.5 \%$ of workers $(n=206)$ and inadequate in $32.5 \%$ of workers $(n=$ 99). It was observed significant association of both, overweight $(\mathrm{p}<0.001)$ and obesity $(\mathrm{p}<0.001)$ with inadequate WC parameters.In relation to the body mass index (BMI), 130 servers were eutrophic $(42.6 \%)$, while 175 workers were overweight $(57.4 \%)$, with $41.0 \%$ considered overweight and $16.4 \%$ considered obese.Turning to the analysis of behavioral characteristics, among workers with past smoking, a prevalence of overweight was found of $77.3 \%$, with $63.6 \%$ being overweight and $13.6 \%$ being obese, which revealed a significant association with overweight and obesity. ( $p=0.003$ ) Those who, in turn, declared themselves to be sedentary, presented a prevalence of overweight of $39.7 \%$, together with a prevalence of obesity of $24 \%$, reaching a rate of $63.3 \%$ overweight. Regarding the sedentary lifestyle, a statistically significant association with overweight and obesity was observed ( $p=0.002)$, as can be observed in table 4.

TABLE 4 Distribution of workers according to life habits, anthropometry and $\mathrm{BMI}(\mathrm{n}=305), 2018$

\begin{tabular}{|c|c|c|c|c|c|c|}
\hline \multicolumn{3}{|c|}{ Characteristics } & \multicolumn{2}{|c|}{ Obesity } & \multicolumn{2}{|c|}{ Overweight } \\
\hline & $\mathrm{N}$ & $\%$ & Prev \% & p-value & $\begin{array}{c}\text { Prev } \\
\%\end{array}$ & p-value \\
\hline $\begin{array}{c}\text { Waist } \\
\text { circumference }\end{array}$ & & & & $<0,001$ & & $<0,001$ \\
\hline Adequate & 206 & 67.5 & 2.9 & & 43.7 & \\
\hline Inadequate & 99 & 32.5 & 44.4 & & 85.9 & \\
\hline $\begin{array}{c}\text { Sedentary } \\
\text { lifestyle }\end{array}$ & & & & 0,002 & & 0,032 \\
\hline Yes & 146 & 47.9 & 24.0 & & 63.7 & \\
\hline No & 159 & 52.1 & 9.4 & & 51.6 & \\
\hline $\begin{array}{l}\text { Smoking } \\
\text { history }\end{array}$ & & & & 0,003 & & 0,004 \\
\hline Yes & 44 & 14.4 & 13.6 & & 77.3 & \\
\hline No & 261 & 85.6 & 16.9 & & 54.0 & \\
\hline
\end{tabular}




\section{DISCUSSION}

The results found among the studied population call attention, due to the causal association between overweight and non-transmissible chronic diseases. (16,17) High prevalence of overweight was found both among women and among men. The prevalence of obesity in the study population was estimated at $16.4 \%$ with $95 \%$ confidence intervals ( $12.2 \%$ up to $20.5 \%$ ), with no divergence from that found in the Brazilian population, which is $18.9 \%$ (BRAZIL, 2016). These results corroborate those of previous study among hospital kitchen workers ${ }^{(18)}$, as well as another one performed among nursing workers. ${ }^{(19)}$ The possibility of a common environmental factor, modulating genetic factors related to the accumulation of fat in these population groups, can't be ignored.

There was predominance, among servers, that those who affirmed to have a diploma of superior level, having been found a statistically significant association between low schooling and overweight. Reinforcing these findings, two studies find a higher prevalence of overweight among professionals with lower educational level. ${ }^{(20,21)}$ Other studies correlate low schooling with an increased risk for the metabolic syndrome (MS), which is repeated with a sedentary lifestyle. This may be related to less access to information about the problem or to a lesser understanding of the importance of what can be accessed, leading to poor therapeutic adherence.

This study found association of overweight and obesity with an habit of working up to 40 hours per week, contrasting with another study that showed a positive association between working more than 12 hours a day and higher rates of overweight and obesity. ${ }^{(21)}$ The amount of time spent on work activities can reduce the time available for physical activities. Thus, socioeconomic characteristics influence the behavioral pattern of the populations, and may interfere in their quality of life. A significant association was found between the exercise of administrative positions and the category of nursing technicians, with overweight and obesity. The exercise of the work activity outside the closed sectors presented a significant association with overweight and obesity. Another study conducted among servants of a university hospital has found results consistent with the administrative stratum. ${ }^{(22)}$ The more rigid work routine may be for professionals in the closed sectors a factor that conducts lo less voluminous meals within a lesser time period, indirectly leading to the adoption of a healthier food habit. Conversely, a more flexible routine may be related to the possibility of aliquots of food at extra hours, in addition to larger intakes.

This study showed an increased prevalence of overweight among patients with self-reported hypercholesterolemia, with a statistically significant association with overweight. The same occurred with the group of servants who called themselves users of antihypertensive medications, who achieved a high prevalence of overweight, which reflects data from a study carried out on a population of obese in the clinics hospital of the Medical College of São Paulo University who found hypercholesterolemia in more than half of the sample, an index that was repeated for arterial hypertension. ${ }^{(23)}$ More than a half of the patients surveyed had a BMI above that considered healthy, and the obese represented less than half of those who had overweight. These figures are worse than national statistics, according to the 1995/96 national health survey. (24) This highlights the problem of the progress of obesity in Americas that occurred in the last decades, mainly related to the worsening of nutritional habits and the growth of the sedentary lifestyle. Regarding waist circumference (WC), the presence of inadequate parameters in a portion of workers was evidenced, but according to the national average. These numbers, however, surpassed those verified in a study carried out among students from three schools in the city of Botucatú. ${ }^{(25)}$ Such results among schoolchildren point to a gloomy future, since the presence of sedentary habits and obesity in adolescence is directly related to development of MS during adulthood.

Among workers with smoking history, a high prevalence of overweight was found, which revealed a significant association between smoking past and overweight, happening the same relation between smoking history and obesity. Other researchers point to a higher proportion of central obesity among smokers than among non-smokers, even among the elderly. ${ }^{(26)}$ The main behavioral factor implicated in the onset of chronic non-transmittable diseases is smoking, and their strength increases among the younger populations with poor purchasing power, as well as in the poorest countries.

The sedentary workers showed a high prevalence of excessive weight, evidencing a statistically significant association with overweight and obesity. Epidemiological and cohort studies point to an association between obesity and physical inactivity, as well as an inverse association between physical activity, BMI and waist circumference. ${ }^{(27)}$

\section{FINAL COMMENTS}

The percentage of hospital workers diagnosed as having excessive weight and the economic-epidemiological representativeness of obesity-related diseases raises the urgency to implement strategies aimed at the control of morbidity related to obesity for this population group.

The inclusion of healthy eating habits and the stimulation of physical exercise are interventions that can be implemented in the work environment; and may act with facilitators of overweight control in this population.

\section{REFERENCES}

[1] Brazil. Ministry of Health.Secretary of Health Care.DepartmentofBasic Attention.Cardiovascular, cerebrovascular and chronic kidney disease clinical prevention. Brasília (DF): Ministry of Health; 2006. 56 p.

[2] Molarius A, Seidell JC. Selection of anthropometric indicators for classification of abdominal fatness - a critical review.Int J Obes. 1998; 22(8):719-27.

[3] World Health Organization. Obesity: preventing and Managing the Global Epidemic. Report of a WHO Consultation. Geneva. WHO Technical Report Series n. 894, p. 1-12, 2004.

[4] Wild S, Roglic G, Green A, Sicree R, King H. Global prevalence of diabetes:estimates for year 2000 and projections for 2030. Diabetes Care. 2004;27(5):1047-53.

[5] WHO (WorldHealthOrganization). Physical Status: The use and interpretation of anthropometry. Technicalreport series, 854. Genebra, 1995 
[6] Velásquez-Meléndez G, Kac G, Valente JG, Tavares R, Silva CQ, Garcia SE. Evaluation of waist circumference to predict general obesity and arterial hypertension in women in Greater Metropolitan Belo Horizonte, Brazil.Public Health Notebooks. 2002; 18(3):765-71.

[7] World Health Organization. Obesity: preventing and managing the global epidemic. Geneva; 1997. Report of a WHO consultation group on obesity.

[8] Heseker H, Schimid A. Epidemiology of obesity. TherUmsch 2000, 57 (8), 478-81.

[9] Edwardson CL, Gorely T, Davies MJ, Gray LJ, Khunti K, Wilmot EG, et al. Association of sedentary behavior with metabolic syndrome: a meta-analysis. PLoS One. 2012;7(4):e34916.

[10] Kim J. Dairy food consumption is inversely associated with the risk of the metabolic syndrome in Korean adults. J Hum Nutr Diet. 2013;26Suppl 1:171-9.

[11] Miller A, Adeli K. Dietary fructose and the metabolic syndrome.CurrentOpinionGastroenterol.2008;24(2):204-9.

[12] Wanderley EM, Ferreira VA. Obesity: a plural perspective. Science\&Collective Health 2010; 15 (1): 185-194.

[13] Gomes JR - Occupational health in the hospital. Journal Paul Hosp, 1974;22:274-276.

[14] Critical Care Medicine, 1999; 27:633-638.

[15] World Health Organization. (WHO). Global strategy on diet, physical activity and health. [Cited in 2009 Jan 1]. Available from: http://www.who. int/gb/ebwha/pdf_files/WHA57/A57_R17-en.pdf

[16] BRASIL. Ministry of Health.Secretary of Health Care.Department of Basic Attention.Strategies for care of the person with chronic disease: obesity. Brasília: Ministry of Health; 2014.

[17] K Lima SírioBoclin, N Blank - Brazilian Journal of Occupational Health, 2006 - redalyc.org.

[18] Vilarinho, RMF; Lisboa, MTL. Diabetes melitus: risk factors between nursing workers. Actapaul. nursing, São Paulo , v. 23, n. 4, p. $557-561, \quad 2010$

[19] Sousa, RMRPet al . Prevalenceof overweight and obesity between shift workers at health units in Teresina, Piauí. Journal of Nutrition, Campinas, v. 20, n. 5, p. 473-482, Oct. 2007.

[20] SILVEIRA, CátiaDaiane Souza et al. Profile of overweight and obesity in nursing workers in intensive and emergency care units. Science\&health, v. 6, n. 3, p. 157-162, 2013.

[21] Maduro, PA et al. Analysis of the nutritional status and level of physical activity of the servers of the university hospital of Petrolina-PE.Brazilian Journal of Sports Nutrition, v. 11, n. 67, p. 856-867, 2017.

[22] Cercato, $\mathrm{C}$ et al .Cardiovascular risk in an obese population. Brazilian Archivesof Endocrinology Metabolism, São Paulo, v. 44, n. 1, p. 45-48, Feb. 2000

[23] Repetto, G; Rizzolli, J; Bonatto, C. Prevalence, risks and solutions in obesity and overweight: Here, There, and Everywhere. Brazilian Archives of Endocrinology Metabolism, São Paulo, v. 47, n. 6, p. 633-635, Dec. 2003

[24] Andreasi, V et al .Physical fitness associated with the anthropometric measurements of elementary school students. J. Pediatrics. (Rio J.), Porto Alegre, v. 86, n. 6, p. 497-502, Dec. 2010 .

[25] Simon JA, Seeley DG, Lipschutz RC, Vittinghoff E, Browner WS. The relation of smoking to Waist-to-Hip Ratio and Diabetes Mellitus among Elderly women. Prev Med 1997;26:639-44.

[26] Ciolac, EG; Guimarães, G V. Physical exercise and metabolic syndrome. Brazilian Journal of Sports Medicine, v. 10, n. 4, p. 319-24, 2004. 